\title{
Análise físico-química e sensorial do pão de batata isento de glúten enriquecido com farinha de chia
}

\author{
Physical, chemical and sensory analysis of gluten-free potato bread enriched with chia flour
}

\author{
Beatriz da Silva Pereira' \\ Bianca da Silva Pereiral \\ Érida dos Santos Cardoso' \\ Juliana Omena Braga Mendonça' \\ Luciana Borges de Souza' \\ Mischelle Paiva dos Santos ${ }^{2}$ \\ Lilia Zago 3 \\ Suzana Maria de Lemos Freitas ${ }^{3}$ \\ 1 Instituto de Nutrição. Universidade do Estado \\ do Rio de Janeiro. Rio de Janeiro, RJ, Brasil. \\ ${ }^{2}$ Instituto de Química. Universidade do Estado do \\ Rio de Janeiro. Rio de Janeiro, RJ, Brasil. \\ ${ }^{3}$ Departamento de Nutrição Básica e \\ Experimental, Instituto de Nutrição. Universidade \\ do Estado do Rio de Janeiro. Rio de Janeiro, \\ RJ, Brasil. \\ Correspondência/ Correspondence \\ Beatriz da Silva Pereira \\ E-mail: besipe89@hotmail.com
}

\section{Resumo}

Introdução: A doença celíaca é uma enteropatia autoimune que afeta indivíduos com intolerância ao glúten, podendo resultar na má absorção de nutrientes. $\mathrm{O}$ tratamento consiste em dieta isenta desta proteína, conduzindo os celíacos à monotonia alimentar; assim, a doença celíaca tem sido objeto de estudos em busca de alternativas alimentares para indivíduos que sofrem desta enfermidade. A chia (Salvia hispanica L.) apresenta-se como opção para a formulação de produtos isentos de glúten, possuindo elevado valor nutricional, com alto teor de ácidos graxos poli-insaturados, minerais, proteínas e fibras. Objetivo: Melhorar as propriedades nutricionais do pão de batata com recheio de ricota e alho-poró utilizando farinha de chia em sua composição. Métodos: Foram realizadas análises físico-químicas e sensoriais nas formulações padrão, com substituição da base amilácea por $25 \%$ e $50 \%$ de farinha de chia. Resultados: Em relação à composição química, observou-se aumento dos teores de umidade, cinzas e lipídios, conforme a adição de maior percentual de farinha de chia, o que era esperado devido a suas propriedades. Já os dados da análise sensorial indicam que os produtos apresentaram boa aceitação, com índice de aceitabilidade maior que $70 \%$, sendo a formulação com $25 \%$ de farinha de chia a mais aceita. Conclusão: A adição de farinha de chia melhora as propriedades nutricionais do pão de batata, oferecendo nova variação de alimentos com caráter funcional e constituindo alternativa de alimento saudável que favorece a diversidade de produtos isentos de glúten.

Palavras-chave: pão de batata; doença celíaca; glúten; chia. 


\section{Abstract}

Introduction: Celiac disease is an autoimmune enteropathy in individuals with gluten intolerance and may result in malabsorption of nutrients. The treatment consists of gluten-free diet, which can lead celiacs into food monotony; so the celiac disease has been object of research on food alternatives to people who suffer from this disease. Chia seed (Salvia hispanica L.) has high nutritional value, with high contents of polyunsaturated fatty acids, minerals, protein and dietary fiber and is an option to develop gluten-free products. Objective: To improve the nutritional properties of potato bread stuffed with ricotta and leek using chia flour in its composition. Methods: Three formulations (standard and with replacement of the base starchy for $25 \%$ and $50 \%$ by chia flour) were prepared and evaluated through physical, chemical and sensory analysis. Results: In terms of physical and chemical composition, it was observed that the addition of chia flour increased levels of moisture, ash and lipids, which was already an expected result due to chia seed properties. Sensory analysis results indicate that potato bread with chia was well accepted, with an acceptability index over $70 \%$, and the formulation containing $25 \%$ chia flour was the most accepted. Conclusion: The addition of chia flour improves the nutritional properties of potato bread, offering a new range of foods with functional character and is a healthy food alternative that promotes diversity in gluten-free products.

Key words: potato bread; celiac disease; gluten; chia.

\section{Introdução}

Os produtos de panificação estão presentes no dia a dia dos brasileiros e representam um consumo expressivo no país, da ordem de $33,5 \mathrm{~kg}$ por ano por pessoa, segundo dados da Associação Brasileira da Indústria de Panificação e Confeitaria (ABIP). Essa quantidade representa um pouco menos da metade da porção recomendada pela Organização Mundial da Saúde (OMS), que é de $60 \mathrm{~kg} /$ capita/ano. $^{1}$

Em geral, o pão é preparado com quatro ingredientes básicos: farinha de trigo, água, sal e fermento, além de outros ingredientes que podem ser adicionados, como açúcar, leite, ovos e 
condicionadores de massa. Destes, a farinha de trigo se apresenta como o componente estrutural da massa devido à presença de glúten, uma proteína que forma finas membranas que retêm bolhas de gás produzidas por agentes que promovem o crescimento da massa. ${ }^{2}$

Todavia, alguns indivíduos se encontram impossibilitados de consumir produtos que contenham glúten devido à intolerância a essa proteína, caracterizando uma enteropatia autoimune denominada doença celíaca. Em sua forma clássica, a doença celíaca se exterioriza principalmente através de severas lesões da mucosa intestinal, resultando em variáveis graus de má absorção de nutrientes, como lipídios, carboidratos, proteínas, ferro, magnésio, zinco e vitaminas lipossolúveis. ${ }^{3}$ O celíaco produz anticorpos contra o glúten que agem no intestino delgado, atrofiando-o de forma total ou subtotal. ${ }^{4}$

O único método eficaz de tratamento da doença celíaca, tanto para indivíduos assintomáticos quanto para sintomáticos, é seguir uma dieta isenta de glúten, podendo assim evitar os sintomas da doença e reduzir o risco de mortalidade. ${ }^{5}$ Por adotarem uma dieta rigorosa durante toda a vida, os celíacos são obrigados, muitas vezes, a retirar de sua alimentação produtos como pães, bolos, biscoitos, entre outros. Estas restrições no poder de escolha, consequentemente, levam os portadores de doença celíaca à monotonia alimentar.,

Algumas opções como farinha de arroz, creme de arroz, amido de milho, farinha de milho, fubá, farinha de mandioca, polvilho doce, polvilho azedo e fécula de batata são utilizadas na fabricação de produtos de panificação sem glúten ${ }^{4}$. Entretanto, essa substituição provoca mudanças sensoriais nos alimentos, modificando seu sabor, textura, hidratação e aparência ${ }^{7}$ e, muitas vezes, por estas farinhas e amidos serem refinados, apresentam baixos teores de micronutrientes e fibra alimentar, um dos fatores responsáveis pelo consumo inadequado desses nutrientes por celíacos. ${ }^{8}$ Outros alimentos passaram a ser utilizados como novas opções para a fabricação de alimentos isentos de glúten e também para o aumento de seu valor nutritivo, como por exemplo, o amaranto, a quinoa e, mais recentemente, a chia.

A chia (Salvia hispânica L.) é uma semente originária da Colômbia e do México que possui alto valor nutricional, com elevado teor de ácidos graxos poli-insaturados ômega-3 e ômega-6 e proteínas, e de minerais como cálcio, ferro e potássio, grande quantidade de fibra alimentar e presença de polifenóis. ${ }^{10,11}$ Assim, a semente de chia, assim como sua farinha, se apresenta como uma nova alternativa para a fabricação de produtos de panificação que não contenham glúten.

O presente trabalho teve como objetivo melhorar as propriedades nutricionais do pão de batata para portadores de doença celíaca, com a adição de farinha de chia, avaliando as características físico-químicas e sensoriais através dos atributos de aceitação global e intenção de compra. 


\section{Metodologia}

Os ingredientes utilizados na formulação da massa do pão de batata isento de glúten foram: fermento biológico fresco, açúcar, leite desnatado, creme de arroz, fécula de batata, farinha de chia, batata com casca, ovos, margarina e sal. Já para o recheio, foram utilizados: azeite, ricota, alho-poró e iogurte natural integral. Todos os ingredientes utilizados para a elaboração do pão de batata foram adquiridos no comércio local do município do Rio de Janeiro. Para obtenção da farinha de chia, a semente foi triturada no liquidificador por cerca de dois minutos. O experimento foi realizado no período de outubro a dezembro de 2012.

\section{Desenvolvimento da formulação}

Para o desenvolvimento de um pão sem farinha de trigo, com características similares às do pão de batata tradicional, foram realizadas diferentes combinações na formulação da base amilácea, constituída inicialmente de $50 \%$ de creme de arroz e $50 \%$ de fécula de batata.

\section{Preparação do pão de batata}

O preparo do pão de batata foi realizado no Laboratório de Técnica Dietética da Universidade do Estado do Rio de Janeiro. Para a elaboração da massa, foram misturados os ingredientes manualmente até a obtenção de uma mistura homogênea, sendo o mesmo procedimento realizado para a elaboração do recheio. Em seguida, foi moldada a massa com o recheio e o pão de batata foi assado em forno pré-aquecido a $180^{\circ} \mathrm{C}$, por 15 minutos. Procedeuse da mesma forma para as demais formulações.

Os pães de batata foram elaborados com diferentes concentrações de farinha de chia em substituição ao creme de arroz e fécula de batata. Na tabela 1, podem-se observar os ingredientes utilizados na formulação padrão (FP), contendo $50 \%$ de creme de arroz e $50 \%$ de fécula de batata; a formulação I (FI), que contém 37,5\% de creme de arroz, 37,5\% de fécula de batata e $25 \%$ de farinha de chia; e a formulação II (FII), que apresenta em sua composição $25 \%$ de creme de arroz, $25 \%$ de fécula de batata e $50 \%$ de farinha de chia. 
Tabela 1. Ingredientes (\%) utilizados nas formulações FP, FI e FII. Rio de Janeiro, RJ, 2012.

\begin{tabular}{cccc}
\hline Ingredientes & FP & FI & FII \\
\hline Creme de arroz & 13 & 9,7 & 6,5 \\
Fécula de batata & 13 & 9,7 & 6,5 \\
Farinha de chia & - & 6,5 & 13 \\
Leite desnatado & 3,2 & 3,2 & 3,2 \\
Ovo & 9 & 9 & 9 \\
Margarina & 4,3 & 4,3 & 4,3 \\
Batata com casca & 27 & 27 & 27 \\
Açúcar cristalizado & 1,5 & 1,5 & 1,5 \\
Sal & 0,9 & 0,9 & 0,9 \\
Fermento biológico fresco & 1,9 & 1,9 & 1,9 \\
Ricota & 13 & 13 & 13 \\
Alho porró & 5,7 & 5,7 & 5,7 \\
Iogurte natural integral & 6,5 & 6,5 & 6,5 \\
\hline Azeite & 1 & 1 & 1 \\
\hline
\end{tabular}

\section{Análise físico-química}

Foram realizadas análises físico-químicas do pão de batata isento de glúten e da farinha de chia no Laboratório de Bromatologia do Instituto de Nutrição da Universidade do Estado do Rio de Janeiro, segundo metodologia do Instituto Adolf Lutz ${ }^{12}$ : determinação de umidade (secagem em estufa a $105^{\circ} \mathrm{C}$ ), cinzas (resíduo mineral por incineração) e proteína bruta (método de Kjeldahl); lipídios totais (método de Bligh e Dyer ${ }^{13}$ ). O teor de carboidratos foi calculado pela diferença entre 100 e a soma dos valores obtidos para umidade, proteína, lipídeos totais e cinzas. Todas as determinações foram feitas em duplicata. 


\section{Análise sensorial}

As análises sensoriais foram realizadas no Laboratório de Técnica Dietética da Universidade do Estado do Rio de Janeiro durante quatro semanas consecutivas, utilizando-se testes afetivos de aceitação por escala hedônica (aceitação global) e intenção de compra. Os provadores, não treinados, foram abordados no campus da universidade, e incluíam estudantes, professores e funcionários de ambos os sexos e ampla faixa etária.

As análises realizadas nas três primeiras semanas contaram com a participação de 35 provadores cada e consistiram em um teste de aceitação por escala hedônica de nove pontos, cujos extremos representam "gostei extremamente" (nota 9) e "desgostei extremamente" (nota 1). Primeiramente, foi realizada a análise sensorial da formulação padrão (FP), e nas semanas que se sucederam, a formulação com $25 \%$ de farinha de chia na composição do pão de batata (FI) e a formulação com $50 \%$ de farinha de chia (FII), respectivamente.

Para avaliar a aceitação do produto, foi calculado o índice de aceitabilidade (IA) de acordo com a fórmula descrita por Bispo et al., ${ }^{14}$ sendo o mesmo considerado de boa aceitação quando o resultado de IA foi maior ou igual a $70 \%$.

\section{IA $(\%)=\underline{\text { Nota média obtida no atributo } \times 100}$ \\ Maior nota dada ao atributo}

A última análise consistiu em um teste de intenção de compra de três pontos (1 - não compraria; 2 - tenho dúvida; 3 - compraria) entre a formulação padrão e a amostra mais aceita dentre as duas formulações com farinha de chia (FI e FII), tendo a participação de 50 provadores não treinados.

\section{Análise estatística}

Os resultados da análise sensorial do pão de batata foram submetidos a análise de variância (ANOVA) e teste de Tukey ao nível de $5 \%$ de probabilidade de erro $(\mathrm{p}<0,05)$, utilizando-se o programa estatístico GraphPad Prism versão 5.0. Já a confecção de gráficos foi realizada no programa Microsoft Office Excel. 


\section{Resultados e discussão}

Análise físico-química do pão de batata

A legislação brasileira atual não dispõe de padrões de identidade e qualidade específicos para produtos de panificação isentos de glúten. Os valores relativos de umidade, cinzas, carboidrato, proteína e lipídio de cada uma das formulações FP, FI e FII estão apresentados na tabela 2.

Tabela 2. Parâmetros físico-químicos do pão de batata para as diferentes formulações. Rio de Janeiro, RJ, 2012.

\begin{tabular}{cccc}
\hline Parâmetros avaliados & FP & FI & FII \\
\hline Umidade $(\mathrm{g} \%)$ & $48,61 \pm 0,63$ & $50,45 \pm 0,25$ & $50,27 \pm 0,72$ \\
Cinzas $(\mathrm{g} \%)$ & $1,66 \pm 0$ & $2,56 \pm 0,07$ & $2,20 \pm 0,02$ \\
Carboidrato $(\mathrm{g} \%)$ & $88,43 \pm 0,63$ & $83,91 \pm 1,71$ & $83,03 \pm 0,78$ \\
Proteína $(\mathrm{g} \%)$ & $4,07 \pm 0,07$ & $7,18 \pm 0$ & $7,59 \pm 0,16$ \\
Lipídio $(\mathrm{g} \%)$ & $7,50 \pm 0,7$ & $10,41 \pm 0,21$ & $9,38 \pm 0,62$ \\
\hline
\end{tabular}

Observa-se que a adição de farinha de chia ao pão de batata proporcionou a elaboração de um alimento com alto valor nutricional, já que com exceção do carboidrato, todos os outros parâmetros analisados aumentaram quando comparados à FP. Este dado ratifica a literatura, segundo a qual a chia apresenta alto teor de proteínas, lipídios e minerais em sua composição.

O teor de lipídios totais, conforme já descrito, aumentou com a adição de farinha de chia. Contudo, isso pode ser visto como um fator positivo, já que as sementes de chia são ricas em ácidos graxos poli-insaturados, particularmente ácidos linolênico (ômega 3) e linoleico (ômega 6), que representam grandes benefícios para a saúde humana. ${ }^{15}$ 
Com a adição de farinha de chia, houve decréscimo no teor de carboidrato. Em geral, os produtos de panificação são considerados alimentos com alto valor energético e pobres nutricionalmente, por serem compostos basicamente de carboidrato. Logo, o acréscimo de farinha de chia contribuiu para a elaboração de um produto com valor nutricional agregado, o que é de grande importância, visto que o pão é um alimento bastante consumido no dia a dia dos brasileiros.

Comparando a formulação padrão com as formulações experimentais, nota-se que o teor de umidade foi maior para as formulações que apresentavam em sua composição farinha de chia. Isso porque, de acordo com a literatura, a chia tem como propriedade a capacidade de absorver mais de 12 vezes seu peso de água, formando um gel devido à presença de fibra solúvel em sua composição. ${ }^{16}$

\section{Análise sensorial: teste de aceitação por escala hedônica}

As figuras a seguir mostram as porcentagens de respostas do teste de aceitação por escala hedônica nas análises sensoriais do pão de batata com relação ao atributo aceitação global e os resultados do IA, respectivamente (figuras 1 e 2).

No que diz respeito à aceitação global, pode-se observar na figura 1 que FI alcançou a maior frequência de notas 8 (gostei muito), correspondendo a 57\%, seguida da FP, com 51\%. Já FII foi a única entre as amostras que obteve frequência de notas inferiores a 6 (gostei ligeiramente), sendo sua maior aceitação correspondente à nota 7 (gostei moderadamente), em torno de 40\%. Não houve diferença estatística significativa entre as amostras.

Assim, quando comparada a FP e FI, verifica-se que a amostra FII apresentou aceitação global inferior às demais. Isso se deve provavelmente à combinação da aparência com baixa aceitação, devido ao escurecimento da massa, consequente à adição de maior quantidade de farinha de chia (50\%), e também de sua textura, que segundo comentários de provadores nas fichas de avaliação, poderia ser mais "leve". 


\section{ACEITAÇÃO GLOBAL}

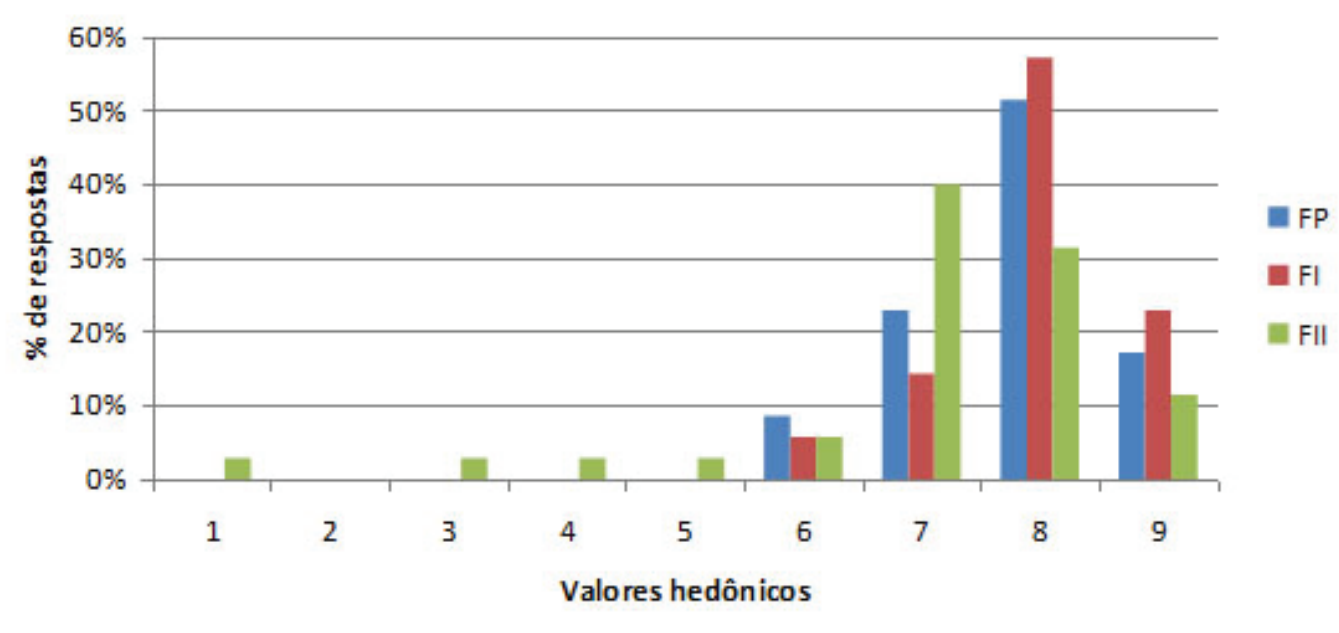

Figura 1. Histograma dos resultados da análise sensorial do pão de batata, em relação à frequência dos valores hedônicos atribuídos à aceitação global $(9=$ gostei extremamente e $1=$ desgostei extremamente).

Pode-se concluir, através da figura 2, que a amostra FI obteve maior índice de aceitabilidade (89\%) no que diz respeito ao atributo "aceitação global”, seguido da formulação FP e FII, com 86\% e 78\%, respectivamente, apresentando boa repercussão e demonstrando resultado satisfatório. Para um produto ser considerado como aceito, é necessário que obtenha IA de no mínimo $70 \% .^{17}$ 


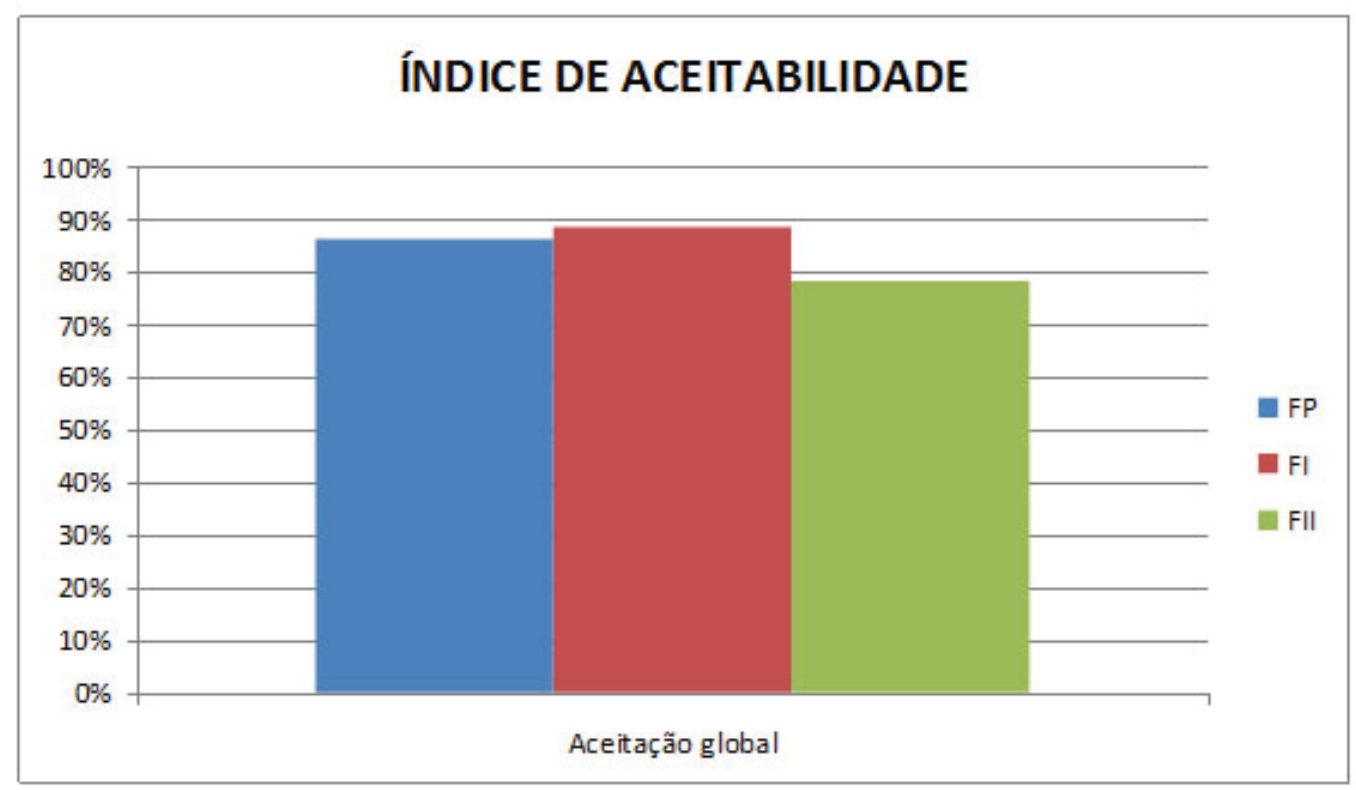

Figura 2. Histograma dos resultados do índice de aceitabilidade (IA) do pão de batata.

A amostra FI obteve a melhor aceitação por parte dos provadores, possivelmente pelo fato de a farinha de chia ter dado ao produto uma textura mais crocante e sabor agradável, enquanto que a aparência ficou um pouco prejudicada devido a uma coloração um pouco escura, não característica do pão de batata. Já FII, apesar de ter também em sua formulação farinha de chia, não foi tão bem aceita quanto FI, visto que a concentração de farinha de chia (50\%) foi alta o suficiente para descaracterizar o pão de batata, não tendo aceitabilidade tão boa em relação a todos os atributos analisados.

\section{Teste de intenção de compra}

Este teste contou com a formulação padrão e a formulação FI (25\%), a mais aceita sensorialmente. Na figura 3, nota-se que para a formulação com $25 \%$ de farinha de chia (FI) houve intenção de compra, já que a maioria dos provadores $(78 \%)$ compraria o produto. Cabe ressaltar que FI apresentou intenção de compra 20\% maior em relação a FP. Alguns comentários dos provadores descreveram a massa como "macia”, sobretudo em relação à amostra FP.

O resultado "não compraria" correspondeu a $4 \%$ e $2 \%$ para a formulação FP e FI, respectivamente. Assim, pode-se afirmar que para ambas as formulações, o produto desenvolvido sem glúten teve aceitação satisfatória, podendo atender aos indivíduos celíacos. 


\section{INTENÇÃO DE COMPRA}

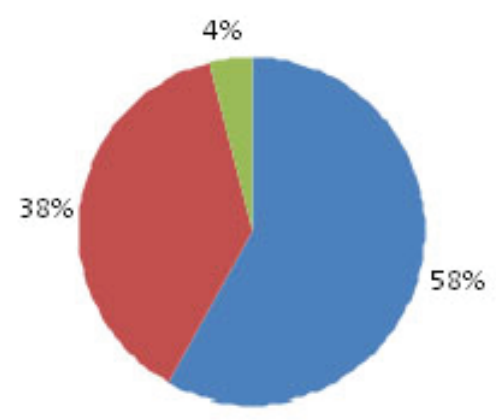

FP

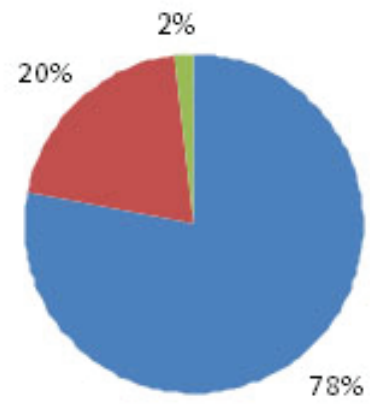

FI

Figura 3. Resultado do teste de intenção de compra.

\section{Conclusão}

O trabalho demonstrou que a adição de farinha de chia melhora as propriedades nutricionais do pão de batata, como observado na redução do teor de carboidratos e aumento no teor de proteínas, minerais e lipídeos insaturados.

A análise sensorial mostrou que o pão de batata isento de glúten elaborado com substituição parcial da base amilácea por $25 \%$ de farinha de chia obteve boa aceitação pela maioria dos provadores, sendo a concentração de $25 \%$ de farinha de chia considerada ideal.

O teste de intenção de compra demonstrou que os consumidores estão mais conscientes para consumir alimentos com alto valor nutricional agregado, já que o pão comum é um produto basicamente composto por carboidratos e destituído de nutrientes importantes para a saúde.

O pão de batata desenvolvido com farinha de chia oferece uma nova variação de alimentos com caráter funcional, constituindo alternativa de alimento saudável e diferenciado, que favorece a diversidade de produtos isentos em glúten, adequados aos portadores de doença celíaca, assim como para os consumidores em geral. 


\section{Referências}

1. Schamne C. Obtenção e caracterização de produtos panificados livres de glúten. [dissertação]. Ponta Grossa: Universidade Estadual de Ponta Grossa; 2007.

2. Ornellas LH. Técnica dietética: seleção e preparo de alimentos. São Paulo: Ateneu; 2001. 142 p.

3. Possik PA, et al. Alimentos sem glúten no controle da doença celíaca. Nutrire. 2005;29:61-74.

4. César AS, et al. Elaboração de pão sem glúten. Ceres. 2006;53(306):150-5.

5. Fasano A, Catassi C. Current approaches to diagnosis and treatment of celiac disease: an evolving spectrum. Gastroenterology. 2001;120:636-65.

6. Zandonadi RP. Psyllium como substituto de glúten [dissertação]. Brasília: Universidade de Brasília. Mestrado em Nutrição Humana; 2006.

7. Andrade AA, et al. Avaliação sensorial de panificação enriquecidos com farinha de feijão branco para pacientes celíacos. Nutrir Gerais. 2011; 5(8):727-39.

8. Thompson T, et al. Gluten-free diet survey: are Americans with coeliac disease consuming recommend amount of fibre, iron, calcium and grain foods? J Hum Nutr Diet. 2005;18(3):163-9.

9. Capriles VD. Otimização de propriedades nutricionais e sensoriais de produtos à base de amaranto enriquecidos com frutanos, para intervenção em celíacos [tese]. São Paulo: Universidade de São Paulo. Faculdade de Saúde Pública; 2009.

10. Reyes-caudillo E, Tecante A, Valdivia-López MA. Dietary fibre content and antioxidant activity of phenolic compounds present in Mexican chia (Salvia hispanica L.) seeds. Food Chem. 2008;107:656-63.

11. Barrientos VA, Aguirre A, Borneo R. Chia (Salvia hispanica) can be used to manufacture sugar-snap cookies with an improved nutritional value. International Journal of Food Studies. 2012;1:135-43.

12. Zenebon O, Pascuet NS. Métodos físico-químicos para análise de alimentos. 4. ed. Brasília: Instituto Adolfo Lutz; 2005. 1018 p.

13. Bligh EG, Dyer WJ. A rapid method of total lipid extraction and purification. Can J Biochem. 1959; 37: 911-7.

14. Bispo ES, et al. Processamento, estabilidade e aceitabilidade de marinado de vongole (Anomalocardia brasiliana). Revista Ciência e Tecnologia dos Alimentos. 2004;24(3):353-6.

15. Uribe JA, et al. Extraction of oil from chia seeds with supercritical CO2. The Journal of Supercritical Fluids 2011;56(2):174-8.

16. Tosco G. Os benefícios da "chia” em humanos e animais. Atualidades Ornitológicas. 2004;119:69 p.

17. Sabatini DR, et al. Composição centesimal e mineral da alfarroba em pó e sua utilização na elaboração e aceitabilidade em sorvete. Revista Alimentos e Nutrição. 2011;22(1):129-36.

Recebido: $10 / 4 / 2013$

Aprovado: 25/5/2013 